\title{
Study of regional cerebral metabolism and blood flow relationships in man using the method of continuously inhaling oxygen-15 and oxygen-15 labelled carbon dioxide
}

\author{
G. L. LENZI' ${ }^{1}$ T. JONES ${ }^{2}$, C. G. MCKENZIE, P. D. BUCKINGHAM, J. C. CLARK, AND \\ S. MOSS
}

From the Medical Research Council Cyclotron Unit, Departments of Radiotherapy and Medical Physics, Hammersmith Hospital, London

SUMMARY A new technique for assessing regional oxygen use and blood flow has been applied to a wide range of neurological patients. The method couples the brain's high metabolic demand for oxygen with a shortlived radioactive form of this metabolite, namely oxygen-15 (half life: $2.1 \mathrm{~min}$ ). This combination produces, during the continuous inhalation of either molecular oxygen-15 or labelled carbon dioxide, steady state functional images of the brain which are relatively free of contribution from extracerebral tissues. These are complementary images in that they relate to regional oxygen uptake and blood flow and hence offer a direct insight to the regional demand-to-supply relationships within the brain in physiological and pathological conditions. In the clinical groups studied, metabolic and circulatory defects were observed and instances of cerebrovascular insufficiency and relative luxury perfusion were defined which hitherto have been deduced from indirect methods. The clinical acceptability of this non-invasive approach allowed us to study those categories of patients which normally do not warrant invasive examination.

The function of the cerebral tissue depends critically on the use of oxygen, its energy turnover being mainly based on glycolytic aerobic metabolism. An impairment in the rate of consumption, because of a failure of either supply or use, often constitutes a pathological condition. It follows that a study of the cerebral blood flow (CBF) and the cerebral oxygen consumption $\left(\mathrm{CMRO}_{2}\right)$ at a regional level is a direct and rational method of investigating cerebral physiology and pathology. The first clinical study of CMRO. and CBF was presented by Kety and Schmidt (1948). Their technique required continuous sampling of arterial and jugular bulb blood, and provided an average measurement of $\mathrm{CMRO}_{2}$ and $\mathrm{CBF}$ for the hemisphere investigated. This method has been used extensively in clinical research but has a limited resolution for investigating focal disease.

While a large number of regional CBF studies have

\footnotetext{
${ }^{1}$ Present address: Department of Neuropsychiatry. Institute of Neurology, University of Siena, Italy.

"Address for reprint requests: Dr T. Jones, MRC Cyclotron Unit, Hammersmith Hospital, Ducane Road, London W12 0HS. England. Accepted 14 July 1977
}

been presented over the last 20 years, the first regional assessment of $\mathrm{CMRO}_{2}$ in man was published by Ter-Pogossian et al. in 1970. This method involves a carotid artery injection of oxygen-15 (2.1 min $\left.\mathrm{T} \frac{1}{2}\right)$ labelled red cells to provide the single passage extraction of oxygen, followed by a similar injection of labelled water for the regional $\mathrm{CBF}$ determination. This technique requires the use of heavily shielded single probes for external recording and so limits the spatial resolution that can be achieved. These methods, although they provide absolute values of $\mathrm{CMRO}_{2}$, have limited application because of their invasiveness.

A non-invasive approach to studying regional metabolism and flow has recently been published by Jones et al. (1976a). The steady state distribution of radioactivity within the brain achieved during the continuous inhalation of oxygen-15 is recorded with a gamma ray imaging device. This distribution is related to the regional oxygen uptake, while a repeat procedure using oxygen-15 labelled carbon dioxide produces a distribution related to regional cerebral circulation. The ratio between the oxygen 
use and circulation images theoretically provides the distribution of the oxygen extraction ratios. The non-invasiveness of this approach, and the indication that relationships between regional oxygen use and flow may be obtained, stimulated us to apply the technique to a series of normal subjects and neurological patients.

This paper summarises the main observations obtained in a group of 25 normal subjects and over 100 neurological patients who were investigated over a six month period, and serves to provide a general insight into the value of this approach.

\section{Theory}

The theory underlying the ${ }^{15} \mathrm{O}_{2}-\mathrm{C}^{15} \mathrm{O}_{2}$ inhalation method was described by Jones et al. (1976a). Inhalation of ${ }^{15} \mathrm{O}_{2}$ results in the formation of labelled oxyhaemoglobin. In the tissues, the oxyhaemoglobin dissociates, and the oxygen- 15 is presented to the cytochrome systems and becomes coupled with $\mathrm{H}^{+}$to form water of the metabolism labelled with oxygen- 15 $\left(\mathrm{H}_{2}{ }^{15} \mathrm{O}\right.$ met. $)$ :

$$
\begin{aligned}
& 2 \text { Cyt. oxidase } \mathrm{Fe}^{1 \frac{1}{2}{ }^{5} \mathrm{O}_{2}-2 \mathrm{H}} \rightarrow \\
& 2 \mathrm{Cyt} \text { oxidase } \mathrm{Fe}^{+}+\mathrm{H}_{2}{ }^{1.5} \mathrm{O}
\end{aligned}
$$

It has been confirmed experimentally that this is the principal fate of the extracted oxygen-15 (TerPogossian et al., 1970), and that contributions to the head signal arising from the presence of oxygen-15 labelled red cells and recirculating $\mathrm{H}_{2}{ }^{15} \mathrm{O}$ metabolism amount to less than $30 \%$ of the total (Jones et al., 1976a). The continuous inhalation of oxygen-15 results in the radioactivity in the tissue reaching a point of equilibrium. This steady state represents the balance between the continuous formation of $\mathrm{H}_{2}{ }^{15} \mathrm{O}$ metabolism, due to the aerobic glycolytic activity of the brain, and the removal of $\mathrm{H}_{2}{ }^{15} \mathrm{O}$ metabolism through radioactive decay and perfusion washout (Jones et al., 1976a). When equating these dynamic processes, the regional $\mathrm{H}_{2}{ }^{15} \mathrm{O}$ metabolism signal is given as:

$$
\mathrm{H}_{2}{ }^{15} \mathrm{O} \text { met. }=\frac{\mathrm{Ca}-\mathrm{CV}}{\mathrm{Cv}} \cdot \mathrm{Ca}^{*} \cdot \frac{(\mathrm{F})}{(\lambda+\mathrm{F} / \mathrm{V})}
$$

where $\lambda$ is the radioactive decay constant of oxygen- 15 $\left(0.335 \mathrm{~min}^{-1}\right)$ and $\mathrm{F}$ the blood flow per minute to a region of volume $\mathrm{V}$. The stable oxygen content of the venous blood draining the tissue is denoted as $\mathrm{Cv}$, while $\mathrm{Ca}$ and $\mathrm{Ca}^{*}$ are the respective stable and radioactive oxygen contents of the arterial blood.

It can be seen that the $\mathrm{H}_{2}{ }^{15} \mathrm{O}$ metabolism has a linear dependence on $\frac{\mathrm{Ca}-\mathrm{CV}}{\mathrm{Ca}}$ which is the tissue's oxygen extraction ratio (OER). The signal's dependence on blood flow is non-linear and introduces the need to examine the flow term of this relationship $\frac{(F)}{(\lambda-F / V)}$ independently. This is achieved by repeating the continuous inhalation study using oxygen- 15 labelled $\mathrm{C}^{1.5} \mathrm{O}$.2. This procedure results in $\mathrm{H}_{2}{ }^{1.5} \mathrm{O}$ being continuously produced in the lung capillary blood (West and Dollery, 1962). Thus the steady state head signal due to the circulating $\mathrm{H}_{2}{ }^{15} \mathrm{O}\left(\mathrm{H}_{2}{ }^{15} \mathrm{O}\right.$ circ. $)$ will contain no metabolic component but only the combined blood flow and radioactive decay terms that are present in the $\mathrm{H}_{2}{ }^{1 .} \mathrm{O}$ metabolism signal:

$$
\mathrm{H}_{2}{ }^{1 .} \mathrm{O} \text { circ. }=\frac{(\mathrm{F})}{(\mathrm{F} / \mathrm{V}: \lambda)} \mathrm{c}
$$

where $\mathrm{c}$ is the arterial concentration of circulating $\mathrm{H}_{2}{ }^{15} \mathrm{O}$. Although non-linear with flow the $\mathrm{H}_{2}{ }^{15} \mathrm{O}$ circulation signal does exhibit a certain sensitivity to flow as shown in Fig. 1.

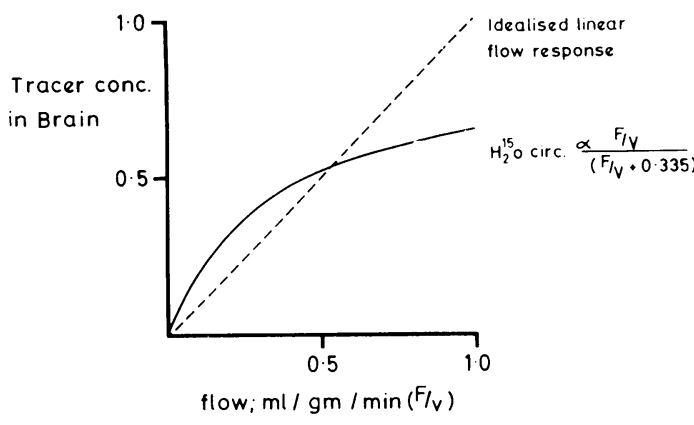

Fig. 1 Theoretical relationship between blood flow and the equilibrium brain tissue concentration of $\mathrm{H}_{2}{ }^{15} \mathrm{O}\left(\mathrm{H}_{2}{ }^{15} \mathrm{O}\right)$ circulation) which results during the continuous inhalation of $\mathrm{C}^{15} \mathrm{O}_{2}$, the arterial blood concentration being taken as unity.

This shows the theoretical change in the brain $\mathrm{H}_{2}{ }^{15} \mathrm{O}$ circulation concentration plotted against $\mathrm{CBF}(\mathrm{F} / \mathrm{V})$ as compared to the ideal linear flow response. For this comparison the two responses have been normalised to the normal average CBF value of $0.53 \mathrm{ml} / \mathrm{min} / \mathrm{g}$. Between zero and normal CBF values the $\mathrm{H}_{2}{ }^{15} \mathrm{O}$ circulation concentration is fairly sensitive to change, while at higher values there is a general tendency to underestimate CBF. Thus the regional $\mathrm{H}_{2}{ }^{15} \mathrm{O}$ circulation cerebral signal does have a place in estimating the distribution of $C B F$; however, its most important role lies in obtaining from the $\mathrm{H}_{2}{ }^{15} \mathrm{O}$ metabolism signal the distribution of the tissue oxygen extraction ratio. This can be realised simply by dividing the $\mathrm{H}_{2}{ }^{15} \mathrm{O}$ metabolism distribution by that due to $\mathrm{H}_{2}{ }^{15} \mathrm{O}$ circulation:

$$
\frac{\mathrm{H}_{2}{ }^{15} \mathrm{O} \text { met. }}{\mathrm{H}_{2}{ }^{15} \mathrm{O} \text { circ. }}=\frac{(\mathrm{Ca}-\mathrm{Cv})}{(\mathrm{Cv})} \frac{\mathrm{Ca}^{*}}{\mathrm{c}}
$$


$\mathrm{Ca}^{*} / \mathrm{c}$ will be a constant for all cerebral regions and hence this normalisation procedure will produce a distribution which represents the regional oxygen extraction ratio. It should be stated that OER is an expression of the balance between the metabolic demand of the cerebral tissue $\left(\mathrm{CMRO}_{2}\right)$ and nutritional supply (CBF). In physiological and pathological terms this balance may be of more interest than regional $\mathrm{CMRO}_{2}$ or $\mathrm{CBF}$.

\section{Methods}

The Medical Research Council's cyclotron was used as a source of oxygen-15. A constant $25 \mu \mathrm{A}$ deuteron beam was used to produce ${ }^{15} \mathrm{O}_{2}$ (target gas: $\mathrm{N}_{2}+1 \% \mathrm{O}_{2}$ ) and $\mathrm{C}^{15} \mathrm{O}_{2}$ (target gas $\mathrm{N}_{2}+1 \% \mathrm{CO}_{2}$ ) (Clark and Buckingham, 1975). The radioactive gases were piped some $210 \mathrm{~m}$ from the cyclotron to the clinical investigation area where the gamma camera was situated. At this location an operator monitored the specific activity of the gas and made dilution adjustments to ensure a constant administration rate to the patient of 1.5 millicuries per minute of oxygen- 15 and 0.75 millicuries per minute of oxygen-15 labelled carbon dioxide. In both cases the total flow rate approximated to $0.51 / \mathrm{min}$. The radioactive gases were in turn administered into a standard oxygen mask worn by the patient who breathed mainly room air through the side holes in the mask. Radioactivity exhaled through the side holes was disposed to waste using an exhaust fan withdrawing air over and around the face mask. Cotton wool was inserted into the patient's nostrils to encourage inhalation through the mouth and minimise the contribution to the radioactivity in the antero-inferior parts of the brain from radioactive gas in the upper airways. During the study the patient lay supine with eyes closed and in a quiet room. The distributions of radioactivity contained within the head were recorded using an Anger camera collima-

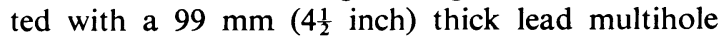
collimator. The performance of this collimator for detecting $511 \mathrm{keV}$ annihilation radiation has been reported previously by Westerman and Glass (1968). The radioactivity within the brain usually attained equilibrium after six minutes of constant inhalation, (Jones et al., 1974) whereupon a four minute steady state image containing between $250.10^{3}$ and $350.10^{3}$ counts was recorded on-line with a computer (HP2100A). The typical time delay between recording the $\mathrm{H}_{2}{ }^{15} \mathrm{O}$ metabolism image and the $\mathrm{H}_{2}{ }^{15} \mathrm{O}$ circulation image was 15 minutes. A total of 15 millicuries of ${ }^{15} \mathrm{O}_{2}$ and 7.5 millicuries of $\mathrm{C}^{15} \mathrm{O}_{2}$ were administered for each paired study. This represents a radiation absorbed dose of 190 millirads and 120 millirads respectively to the lung tissue (critical organ).
The corresponding absorbed doses to the blood are 70 millirads and 110 millirads, and to the gonads 15 and 25 millirads. The computer-stored images were then corrected for the non-uniformity of the Anger camera, smoothed, and displayed for photography. In addition the regional counts were normalised to the counts contained within the area of maximal uptake and printed out in matrix form for subsequent digital analysis.

\section{Results}

The study was performed on 127 subjects, 25 normal volunteers and 102 patients. The Table summarises the two groups, with respect to mean age and sex

Table Summary of mean age and sex ratio of subjects studied

\begin{tabular}{|c|c|c|c|}
\hline & Number & $\begin{array}{l}\text { Mean age } \\
(y r)\end{array}$ & $\begin{array}{l}\text { Male:female } \\
\text { ratio }\end{array}$ \\
\hline Normal volunteers & 25 & 39.9 & $2: 1$ \\
\hline \multicolumn{4}{|l|}{ Patients } \\
\hline Cerebrovascular disease & 33 & 57.7 & $1.6: 1$ \\
\hline Brain tumours & 38 & 48.7 & $1.6: 1$ \\
\hline Extrapyramidal disorders & 18 & 58.0 & $1.8: 1$ \\
\hline Other & 14 & 47.4 & $0.6: 1$ \\
\hline
\end{tabular}

ratio. Neurological patients were further divided into three main subgroups: tumours, cerebrovascular diseases, and extrapyramidal diseases. A few other miscellaneous conditions, including some psychiatric disorders, were investigated.

\section{NORMAL VOLUNTEERS}

The distributions of radioactivity recorded in two normal subjects during continuous inhalation of ${ }^{15} \mathrm{O}_{2}$ and $\mathrm{C}^{15} \mathrm{O}_{2}$ are shown in Fig. 2 . In both subjects the left dominant hemisphere was nearest to the gamma-camera. The pictures clearly show positive images of the brain, due to $\mathrm{H}_{2}{ }^{15} \mathrm{O}$ metabolism when the subjects inhale ${ }^{15} \mathrm{O}_{2}$, and to $\mathrm{H}_{2}{ }^{15} \mathrm{O}$ circulation when $\mathrm{C}^{15} \mathrm{O}_{2}$ is inhaled. It can be seen that the extracerebral structures contribute little to the head image. This could be predicted from the theory (see Fig. 1), when considering the relatively low blood flow and volumes of these tissues. Some degree of contamination was observed in the antero-inferior regions of the brain, because of the gaseous ${ }^{15} \mathrm{O}_{2}$ and $\mathrm{C}^{15} \mathrm{O}_{2}$ contained in the upper airways. This interference was greatest with ${ }^{15} \mathrm{O}_{2}$, because of its lower extraction in the lungs. The distributions of $\mathrm{H}_{2}{ }^{15} \mathrm{O}$ metabolism and $\mathrm{H}_{2}{ }^{15} \mathrm{O}$ circulation are not uniform throughout the brain. The geometrical shape of the brain has to be taken into account, the maximal activity being recorded in the inferior parts, where in transverse 


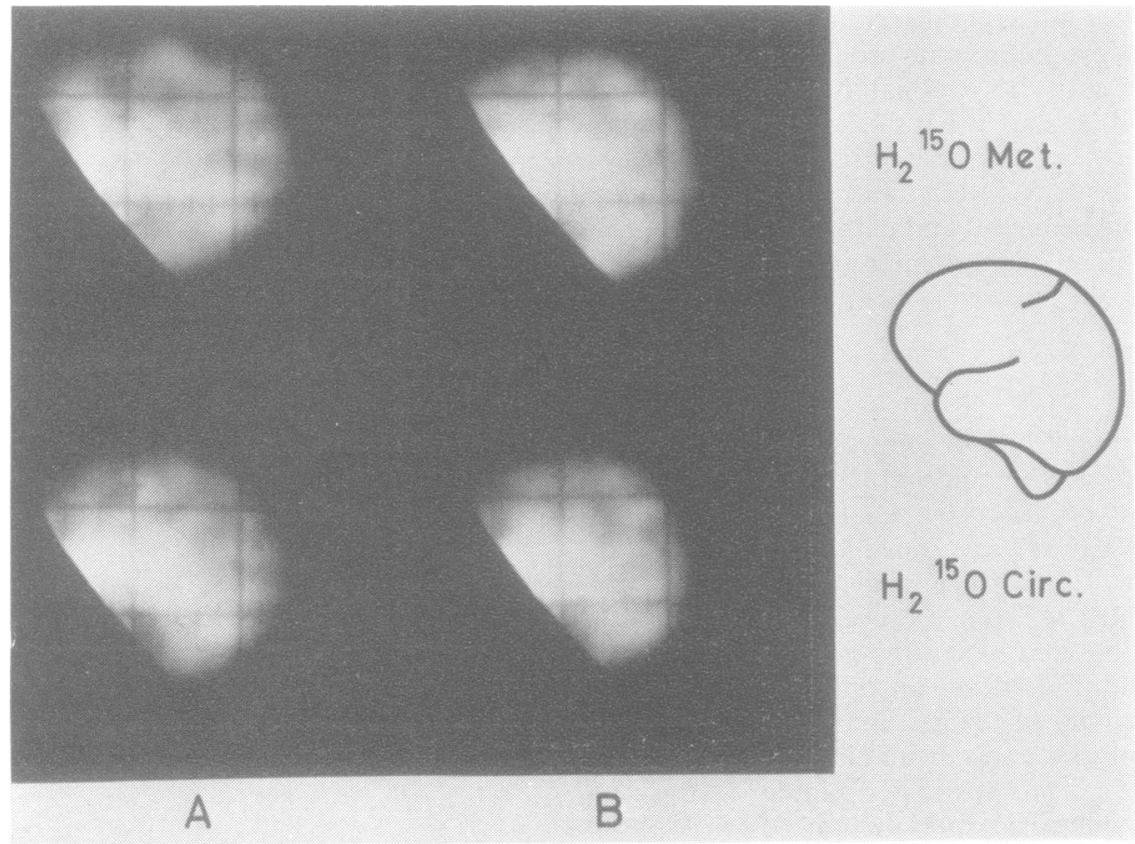

Fig. 2 Equilibrium! distributions of $\mathrm{H}_{2}{ }^{15} \mathrm{O}$ metabolism and $\mathrm{H}_{2}{ }^{15} \mathrm{O}$ circulation as recorded in the left lateral views of two normal brains during the continuous inhalation of ${ }^{15} \mathrm{O}_{2}$ and $\mathrm{C}^{15} \mathrm{O}_{2}$ respectively.

projection there is more cerebral tissue. In addition to the shape-dependence, a definite uptake pattern is superimposed which was largely similar in all the normal subjects investigated under the age of 50 years. The inferior part of the brain had two regions of maximal $\mathrm{H}_{2}{ }^{15} \mathrm{O}$ metabolism activity, one in the supratentorial region, in the middle part of the temporal lobe, the other in the posterior fossa, at mesencephalic - pontine level. Although the distribution of $\mathrm{H}_{2}{ }^{15} \mathrm{O}$ circulation activity is similar, these two regions are less prominent. In the superior part of the brain, regions with lower activity are intermingled with regions of greater activity in both the $\mathrm{H}_{2}{ }^{15} \mathrm{O}$ metabolism and $\mathrm{H}_{2}{ }^{15} \mathrm{O}$ circulation distributions. This aspect must be referred to the presence of "areas containing white matter and ventricles" (Jones et al., 1976a). Furthermore, there is a suggestion of a contribution to physiological activity of the different cortical regions, a finding also observed by other authors (Wilkinson et al., 1969; Risberg et al., 1975). In addition to the analogue picture obtained from the computer, the corresponding numerical matrices were used for an objective analysis of regional cerebral uptake. In both the $\mathrm{H}_{2}{ }^{15} \mathrm{O}$ metabolism and $\mathrm{H}_{2}{ }^{15} \mathrm{O}$ circulation distributions, six regions, each approximately $6 \mathrm{~cm}^{2}$ in area, were selected (frontal, motor, parietal, occipital, temporal, and pontomesencephalic). The average matrix count within each region was ratioed to the average matrix count contained within the region of maximal uptake, which was usually the middle temporal lobe or the pontomesencephalic region. These regional ratios have been designated as Metabolic Ratios (MRs) and Perfusion Ratios (PRs) for the ${ }^{15} \mathrm{O}_{2}$ and $\mathrm{C}^{15} \mathrm{O}_{2}$ studies respectively. In turn, the six regions evaluated within the $\mathrm{H}_{2}{ }^{15} \mathrm{O}$ metabolism distributions (Metabolic Ratios) were normalised to the corresponding regions in the $\mathrm{H}_{2}{ }^{15} \mathrm{O}$ circulation distributions (Perfusion Ratios). This theoretically provides a distribution of the OER which is largely independent of geometrical factors (see equation 3 in Theory Section). Although quantitative, there will be a background superimposed on the regional Perfusion, Metabolic, and Oxygen Extraction Ratios of the ipsilateral hemisphere because of radioactivity in the contralateral hemisphere. This contribution will be variable and will tend to reduce the sensitivity which these ratios have for detecting perturbations from the normal.

Figure 3 illustrates the results of applying this analysis to data obtained in the normal subjects. The mean value and the standard deviation from the mean for these indices in the six regions chosen for the analysis are shown. Since the age of the normal subjects ranged from 22 to 71 years, an increase in the variability was to be expected because of the $\mathrm{CBF}$ and $\mathrm{CMRO}_{2}$ decrease in aging (Scheinberg et al., 1953). In fact, subjects over 50 years of age had slightly increased OERs and decreased MRs and PRs in comparison to the younger subjects (Lenzi et al., in 


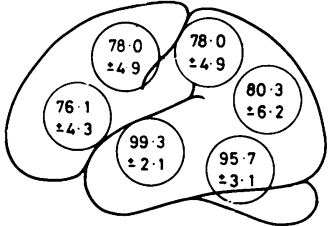

M.R.

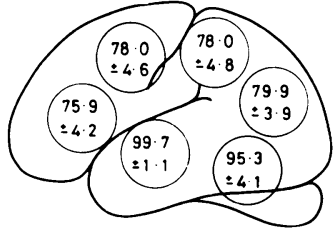

P.R.

Fig. 3 Quantitative distribution of the Metabolic Ratios (MR) and Perfusion Ratios (PR) in 25 normal subjects as determined for six representative cerebral regions. The aistribution of the Oxygen Extraction Ratios obtained by. normalising the Metabolic Ratios to the corresponding Perfusion Ratios is also shown.

NORMAL

SUBJECTS

GROUP

$n=25$

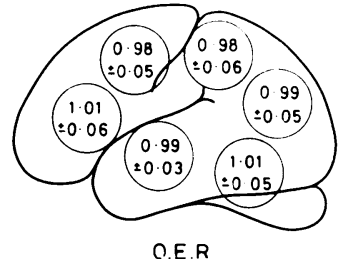

O.E.R preparation). The OER shown in this figure demonstrates the close relationship between the distribution of oxygen uptake and flow, as observed by Raichle 't al. (1976) with the intracarotid injection method.

\section{NEUROLOGICAL DISORDERS}

Over 100 neurological patients were investigated during a six month period. The different neurological groups studied are listed in the Table. A more detailed evaluation of the three major groups-cerebrovascular disease, brain tumours, and extrapyramidal disorders - will be presented in subsequent publications. In this report we will confine ourselves to describing the main perturbations in the distributions of the $\mathrm{H}_{2}{ }^{15} \mathrm{O}$ metabolism and $\mathrm{H}_{2}{ }^{15} \mathrm{O}$ circulation observed within the neurological group.

In general we expect that the present technique would detect a regional decrease in metabolism and circulation, a regional increase in metabolism and circulation, and an imbalance between the regional metabolism and circulation.

\section{Regional decrease in metabolism and circulation}

The most common instances of a parallel decrease in the $\mathrm{H}_{2}{ }^{15} \mathrm{O}$ metabolism and $\mathrm{H}_{2}{ }^{15} \mathrm{O}$ circulation uptakes were seen in stroke patients who had a permanent occlusion of the affected cerebral arteries, and in patients with primary malignant and secondary brain tumours. All these pathological processes produce gross variations in both the neuronal activity and cerebral function. The parallel circulatory decrease observed was either the primary cause of the disease, as in the strokes, or signified a lower metabolic demand from the tumour's cells relative to the neurones. Figure 4 shows the results obtained in a patient in whom computerised axial tomography

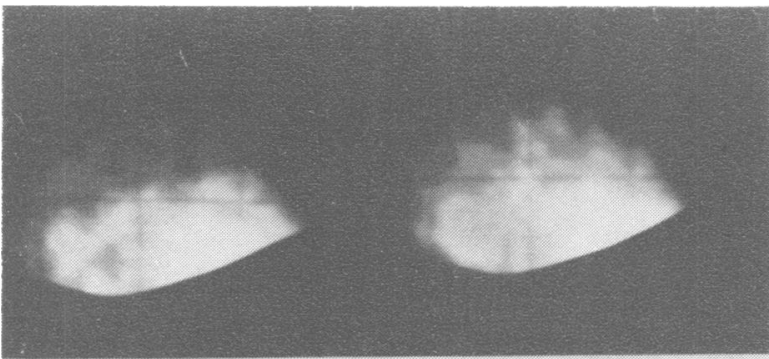

$\mathrm{H}_{2}{ }^{15} \mathrm{OMet}$. $\quad \mathrm{H}_{2}{ }^{15} \mathrm{O}$ Circ.

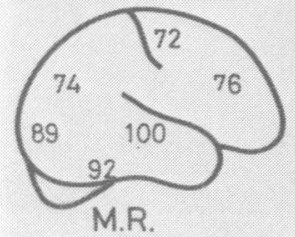

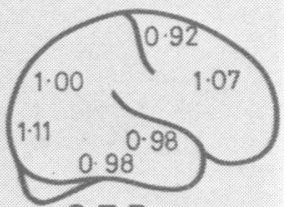

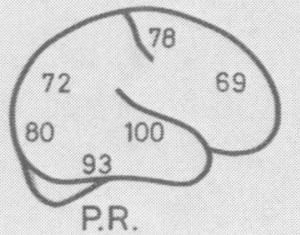

Fig. 4 Distribution of $\mathrm{H}_{2}{ }^{15} \mathrm{O}$ metabolism and $\mathrm{H}_{2}{ }^{15} \mathrm{O}$ circulation in the right lateral view of a patient with diagnosed cerebral atrophy and multiple cerebral infarctions. Although both metabolism and perfusion are regionally. reduced the relative balance between the two is near normal. 
demonstrated "a severe cerebral atrophy, with moderate dilatation of ventricles, and numerous cortical translucencies suggesting multiple infarcts". Both $\mathrm{H}_{2}{ }^{15} \mathrm{O}$ metabolism and $\mathrm{H}_{2}{ }^{15} \mathrm{O}$ circulation images show an impairment of the radioactivity uptake in the superior region of the brain. Some degree of circulation is observed in the proximity of the middle cerebral artery, as if the process were affecting mainly the smaller arterial branches. Analogue images of the radioactive distribution in the brain are subject to contrast enhancement in the display and photographic process. In all examples the corresponding perfusion and metabolic images were normalised quantitatively to each other in the computer so that the same number of counts were present in the regions of maximal uptake. Thus photographic recordings of the two images were always made under the same conditions of contrast and intensity.

\section{Regional increase in metabolism and circulation}

In our series no paralled increases in the $\mathrm{H}_{2}{ }^{15} \mathrm{O}$ metabolism and $\mathrm{H}_{2}{ }^{15} \mathrm{O}$ circulation uptakes were observed, such as might be expected within an active epileptic focus as reported by Hougaard et al. (1976). We must underline that we have not had the opportunity of studying epileptic patients (only a few patients had had fits, and no fits occurred during an investigation).

Increases of $\mathrm{H}_{2}{ }^{15} \mathrm{O}$ circulation activity in a lesion were found to parallel the angiographic and neurosurgical findings of increased blood supply. An example of this is shown in Fig. 5 which presents the images obtained in a patient with a highly vascularised meningioma. The position and rich filling of the tumour vessels is shown in the carotid angiogram. The $\mathrm{H}_{2}{ }^{15} \mathrm{O}$ circulation image endorses these findings while the $\mathrm{H}_{2}{ }^{15} \mathrm{O}$ metabolism image is within the normal limits. The correlation of the two distributions shows a decreased OER in the region of the meningioma.

Imbalance bet ween regional metabolism and circulation Examples of imbalance between the metabolic and circulating distributions were also seen in patients without tumours. This uncoupling between flow and metabolism could not have been predicted, and is thus of greater interest with respect to the relevance of these measurements in the interpretation of neurological disorders. The mismatching of the two distributions may reveal a pathological condition that is not actually producing symptoms or anatomically definite lesions. For instance, we were able to

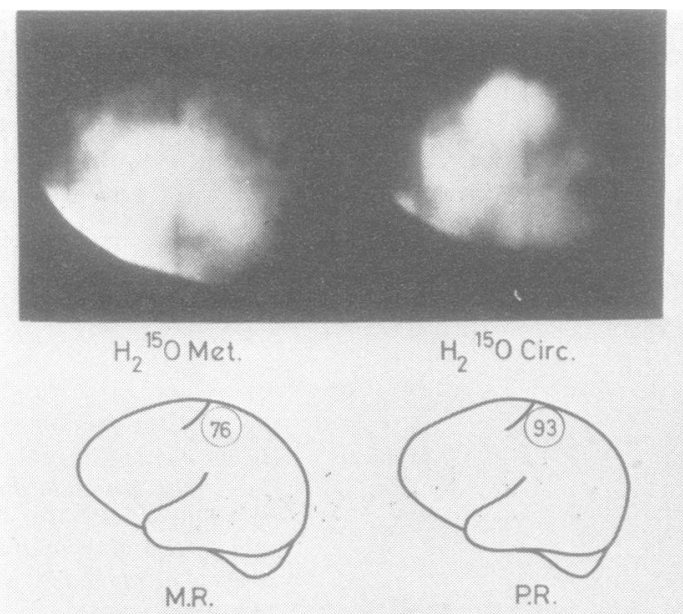

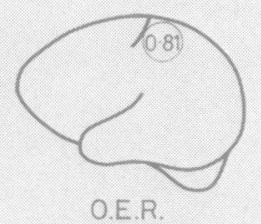

Fig. 5 Distribution of $\mathrm{H}_{2}{ }^{15} \mathrm{O}$ metabolism and $\mathrm{H}_{2}{ }^{15} \mathrm{O}$ circulation in the left lateral view of a patient with a highly vascularised meningioma. The observed area of luxury perfusion correlates anatomically with the tumour"s angiographic blush.

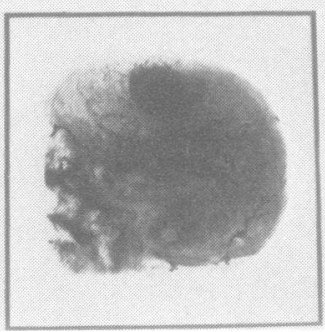


"visualise" areas of clinically silent cerebrovascular insufficiency, where a reduction in circulatory activity was not accompanied by, or was greater than the reduction in metabolic activity. This was observed in asymptomatic cases who had previously presented with transient ischaemic attacks, an example of which is shown in Fig. 6. In this case, the impairment of $\mathrm{H}_{2}{ }^{15} \mathrm{O}$ circulation activity was larger than that of the $\mathrm{H}_{2}{ }^{15} \mathrm{O}$ metabolism activity. The slight decrease in metabolic activity in the parietal region indicated that no definite lesion had occurred and this was confirmed by the patient's neurological history. However, an ischaemic region, where there is preserved neuronal activity coupled with a decrease in the blood supply, indicated that the cerebrovascular insufficiency had not caused neuronal damage. Corresponding to the decrease in the PR there was an increase in the OER.

The reverse pattern-that is, unaffected flow but reduced metabolism - was observed in "stroke" patients with a normal angiography. Figure 7 shows the distributions obtained in a patient in whom computerised axial tomography had demonstrated an infarct in the left frontotemporal region. The $\mathrm{H}_{2}{ }^{15} \mathrm{O}$ metabolism shows a definite triangular area of decrease in the frontal region extending downward to the temporal pole. In contrast, the $\mathrm{H}_{2}{ }^{15} \mathrm{O}$ circulation image shows no defect, and provides evidence of a relative luxury perfusion situation where there is an excess of blood flow with respect to the metabolic needs of the tissue. In such a situation the reduced use of oxygen points to permanent neuronal damage because of the transient reduction of blood flow. The clear-cut defect in the $\mathrm{H}_{2}{ }^{15} \mathrm{O}$ metabolism picture also demonstrates that the arterial recirculation of the metabolically produced labelled water does not appear to affect significantly the resolution that this technique has for demonstrating metabolic defects.

The general comparison between the present technique and the other neuroradiological examinations proved it satisfactory in detecting and locating lesions and in assessing their size and shape. However, the important aspect of these studies is not detection of lesions but investigation of the effect of lesions on cerebral metabolism and blood flow. A preliminary report on the use of this method to assess the effect of radiotherapy on cerebral tumours has already been published by Jones et al. (1976b). The non-invasiveness of the method allows examination of patients such as those with Parkinson's disease in whom such investigations as carotid catheterisation are usually unjustified. This particular aspect is exemplified in Fig. 8. This patient had a two year history of a very mild right extrapyramidal disease which required only anticholinergic treatment to obtain a good control. Surprisingly, a large impairment particularly in the $\mathrm{H}_{2}{ }^{15} \mathrm{O}$ metabolism uptake was detected in the left hemisphere which was contralateral to the side presenting the extrapyramidal signs. In this case the right hemisphere study showed fairly normal distributions with no mismatching of metabolism to perfusion (Fig. 8). The frequency of such aspects in extrapyramidal disorders as seen when using this technique is of interest and justifies a more intensive investigation of this particular group of patients.

There was concern that the superimposition of the

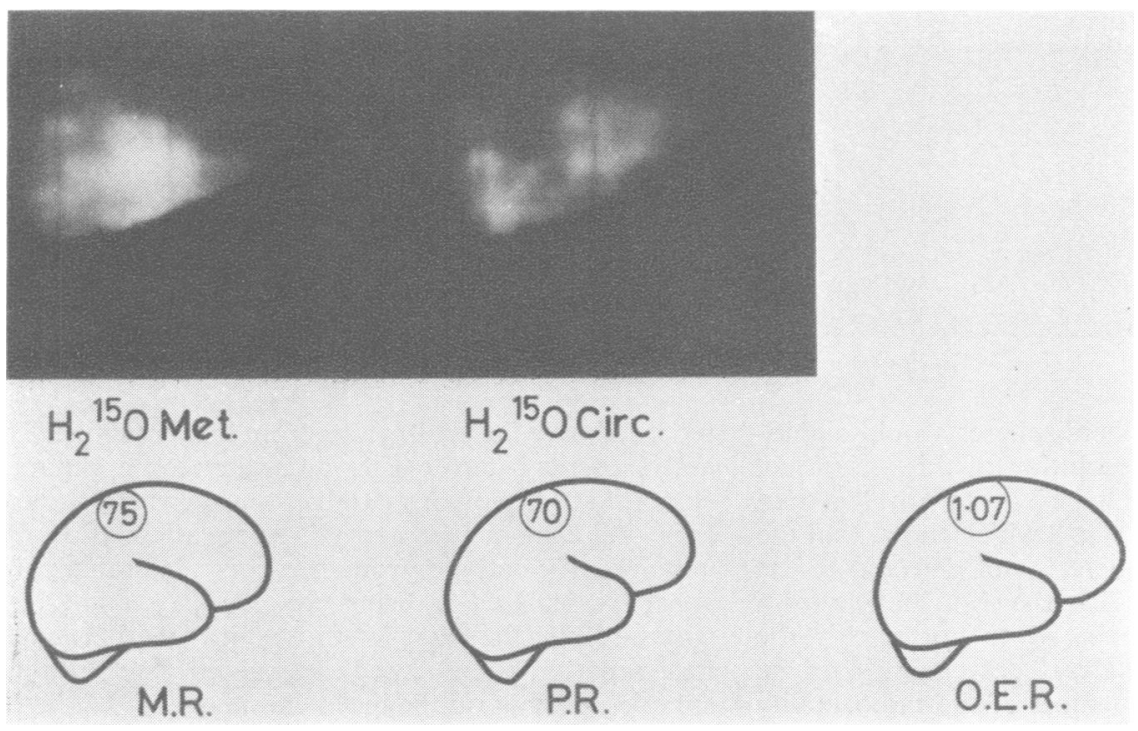

Fig. 6 Distribution of $\mathrm{H}_{2}{ }^{15} \mathrm{O}$ metabolism and $\mathrm{H}_{2}{ }^{15} \mathrm{O}$ circulation in the right lateral view' of a patient presenting with symptoms of transient ischaemic attacks. A zone of ischaemia is seen in the parietal region. 


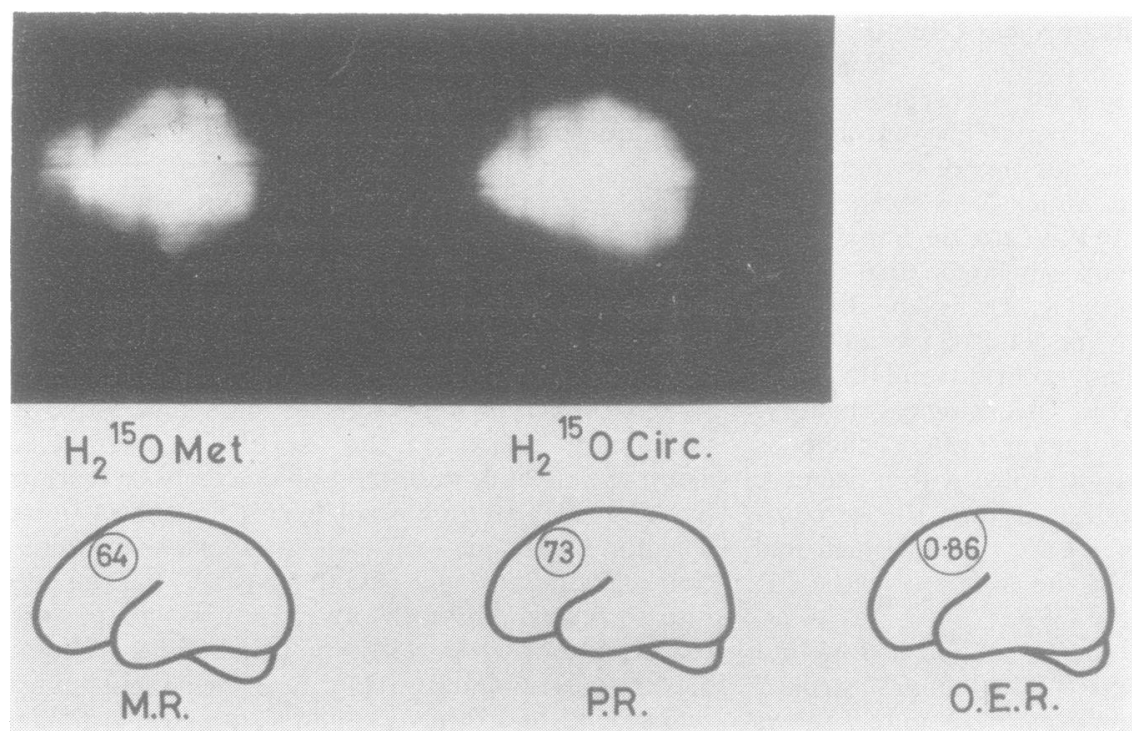

Fig. 7 Distribution of $\mathrm{H}_{2}{ }^{15} \mathrm{O}$ metabolism and $\mathrm{H}_{2}{ }^{15} \mathrm{O}$ circulation in the left lateral view of a stroke patient with a lesion diagnosed in the frontotemporal region from the CAT scan. The isotope study indicates a relative luxury perfusion at this site (which had been found to be normal on angiography).

\section{Left}

\section{Right}

\section{$\mathrm{H}_{2}^{15} \mathrm{OCirc}$}
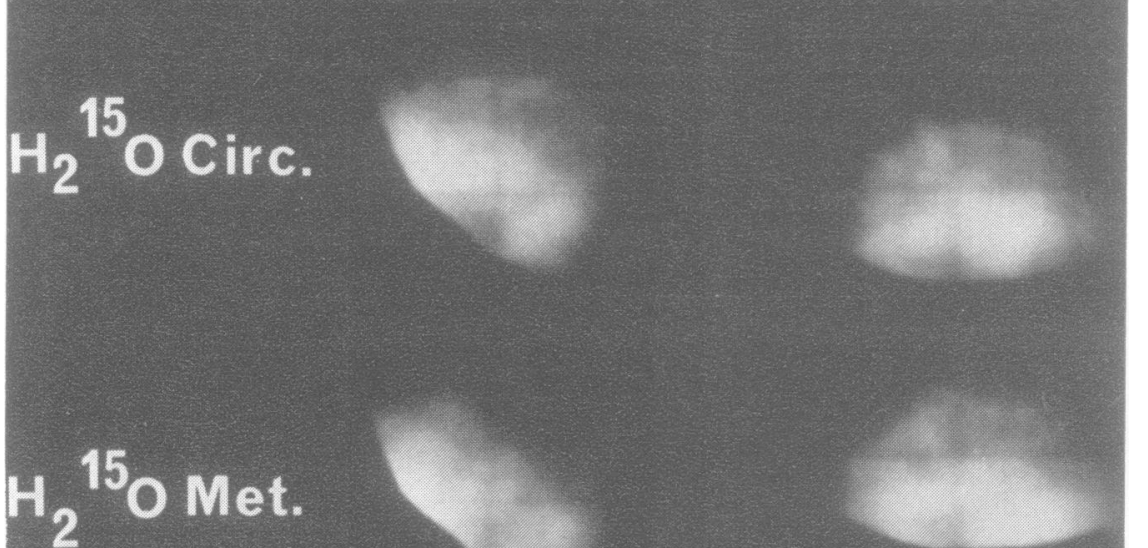

Fig. 8 Distribution of $\mathrm{H}_{2}{ }^{15} \mathrm{O}$ metabolism and $\mathrm{H}_{2}{ }^{15} \mathrm{O}$ circulation in the left and right lateral views of a patient with a two year history of very mild extrapyramidal disease. A decreased metabolic activity is seen in the left parieto-occipital region while the right hemisphere exhibits a normal metabolism/ perfusion balance.

radioactivity in the two hemispheres would significantly impair the focal resolution of this technique. In practice this turned out to be less of a problem than expected as illustrated in Fig. 8 which shows that the defect in the left hemisphere is not detected in the right view. This suggests that the contribution from the contralateral hemisphere does not impair the ability to detect an ipsilateral defect, and can be explained by the fact that most of the radioactivity recorded over the brain arises from the metabolically active cortical grey matter adjacent to the gamma camera. The fall-off of spatial resolution with distance from the camera face and the tissue attenuation of gamma rays emitted from the contralateral hemisphere, calculated as being between $45 \%$ and $65 \%$ (mean $57 \%$ ), results in the contralateral signal behaving as a defocused attenuated background superimposed upon the ipsilateral image. 


\section{Discussion}

The rationale of the present approach rests in coupling the high aerobic metabolic demand of the cerebral tissues with a short half life radionuclide of oxygen. This in effect produces a high differential between the concentration of radioactivity in the brain and extracerebral tissues. Thus it is possible to produce a direct functional image of the brain with a negligible extracerebral contribution, and still administer the labelled oxygen through a general and physiological pathway-namely, inhalation. In addition, repeated investigations showed that these images were reproducible. The study was performed by recording the lateral projection and hence a superimposition of activity from both hemispheres would be expected. However, in detection of focal pathology in the ipsilateral hemisphere, we observed a close agreement with other neuroradiological investigations. This can be explained by the interference from the contralateral hemisphere behaving as a diffuse background, a consequence of the sharp decrease in spatial resolution with distance from the camera and some attenuation of photons $(57 \%)$ in the interposing tissue. For display purposes the intensity and contrast is adjusted to illustrate any focal mismatching between flow and metabolism. This is legitimate provided both images have been normalised to the counts in the region of maximal uptake, an adjustment which helps to supress the effect of the background due to activity in the contralateral hemisphere. Hence mismatching is more dramatically illustrated in the analogue images than from quantitative ratios which are directly subjected to the background effect.

The interference with the $\mathrm{H}_{2}{ }^{15} \mathrm{O}$ metabolic cerebral signal due to recirculating $\mathrm{H}_{2}{ }^{15} \mathrm{O}$ was demonstrated in animals to be less than $30 \%$ (Jones et al., 1976a). This low interference was substantiated in those cases in our series which presented a metabolic lesion with preserved blood flow (Fig. 7). The analogue and digital distributions of $\mathrm{H}_{2}{ }^{15} \mathrm{O}$ metabolism and $\mathrm{H}_{2}{ }^{15} \mathrm{O}$ circulation obtained are in addition to regional and structural physiological differences dependent on the brain's geometry. In our normal series the regional variations were found to be sufficiently consistent to enable the identification of pathological features. The ratio between the $\mathrm{H}_{2}{ }^{15} \mathrm{O}$ metabolism distribution and $\mathrm{H}_{2}{ }^{15} \mathrm{O}$ circulation produces the distribution of the OER which is largely independent of the brain's geometry (equation $3)$. This ratio represents the balance between the metabolic demand $\left(\mathrm{CMRO}_{2}\right)$ and the blood supply (CBF), and is, therefore, a direct expression of the physiological condition of the nervous tissue. A striking outcome of the application of this approach to a neurological population has been the positive demonstration of instances of true cerebrovascular insufficiency - that is, a situation of low flow with preserved metabolic activity, and of relative luxury perfusion where there is normal flow but reduced regional metabolism. These situations until now have been only indirectly inferred. In addition, unsuspected impairments have been observed in neurological patients such as those with extrapyramidal disorders which, to date, not being ethically suitable for invasive investigation, were only evaluated with clinical examination. No evident increase in regional metabolism was observed, in contrast to recent experimental observations (Reivich, 1976 unpublished), but it should be emphasised that the present technique detects only aerobic glycolytic metabolism.

The main limitation of this work has been the lack of absolute quantitative measurement of regional $\mathrm{CMRO}_{2}$ or $\mathrm{CBF}$. The theory indicates that such parameters may be extracted from the steady state uptake of $\mathrm{H}_{2}{ }^{15} \mathrm{O}$ metabolism and $\mathrm{H}_{2}{ }^{15} \mathrm{O}$ circulation provided quantitative regional uptake measurements are performed and related to the corresponding arterial blood concentrations (Jones et al., 1976a). This is technically difficult when using a conventional Anger camera, and is best performed with imaging devices which employ positron-coincidence detection. Tomographic emission studies of cerebral uptake would eliminate the superimposed position of tissue signals, and hence greatly advance the method by virtue of improved detection contrast. The most practical technical approaches to both quantitation and tomography would appear to be either the PETT system developed by Ter-Pogossian et al. (1975) or the Positron camera of Brownell (Brownell and Burnham, 1972; Hoop et al., 1976). It should be emphasised, however, that, even when these sophisticated devices are used, arterial sampling will be necessary to obtain absolute regional CMRO.2 or CBF values.

The acceptability of this non-invasive method is underlined by the fact that out of more than 100 patients studied, only one refused to cooperate. Therefore, it seems logical to speculate upon a larger application to the complete spectrum of neurological and psychiatric disorders. The modifications of the distributions observed in old normal subjects indicate that this approach could be relevant in the investigations of aging processes. A logical progression of our approach would be the evaluation of therapeutic agents in neurological disorders (Jones et al., 1976b). In particular, our demonstration of ischaemia is a positive example where an objective assessment of therapy could be obtained. 
The continuous support of this work by $\mathrm{Mr} \mathrm{D}$. $\mathrm{D}$. Vonberg and Dr R. Morrison is acknowledged. The success of this study has rested closely on the cooperation of those neurologists who referred patients to us from outside our institutes. In particular our colleagues at the following London centresHammersmith, Central Middlesex, Royal Free, and National Hospital for Nervous Diseases-are acknowledged for the interest they have shown in these investigations. We are deeply indebted to Professor J. Marshall and to Professor C. Fieschi for their invaluable suggestions and criticisms in the preparation of this manuscript. The technical support of Mr P. J. Sleight and the cyclotron operating team is recognised as having been of utmost importance. Dr Lenzi was supported by NATO and the National Research Council of Italy Grant Number 215.7 (1974).

\section{References}

Brownell, G. L., and Burnham, C. A. (1972). MGH positron camera. In Tomographic Imaging in Nuclear Medicine. Edited by F. S. Freedman, pp. 154-164. Society of Nuclear Medicine: New York.

Clark, J. C., and Buckingham, P. D. (1975). Short lived Radioactive Gases for Clinical Use. Butterworths: London.

Hoop, B., Hnatowich, D. J., Brownell, G. L., Jones, T., McKusick, K. A., Ojemann, R. G., Parker, J. A., Subramanyam, R., and Taveras, J. M. (1976). Techniques for positron scintigraphy of the brain. Journal of Nuclear Medicine, 17, 473-479.

Hougaard, K., Oikawa, T., Sveinsdottir, E., Skinhøj, E., Ingvar, D. H., and Lassen, N. A. (1976). Regional cerebral blood flow in focal cortical epilepsy, Archives of Neurology (Chicago), 33, 527-535.

Jones, T., Brownell, G. L., and Ter-Pogossian, M. M. (1974). Equilibrium images of short-lived radiopharmaceuticals for dynamic observations. Journal of Nuclear Medicine, 15, 505.

Jones, T., Chesler, D. A., and Ter-Pogossian, M. M. (1976a). The continuous inhalation of oxygen-15 for assessing regional oxygen extraction in the brain of man. British Journal of Radiology, 49, 339-343.

Jones, T., McKenzie, C. G., Moss, S., Buckingham, P. D., and Clark, J. C. (1976b). The non-invasive use of oxygen-15 for studying regional brain function in patients with cerebral tumours. Proceedings of the 12th Bad Gastein Symposium on Radioactive Isotopes in Clinical Medicine and Research.

Kety, S. S., and Schmidt, C. F. (1948). The nitrous oxide method for the quantitative determination of cerebral blood flow in man: theory, procedures and normal values. Journal of Clinical Investigation, 27, 476-483.

Raichle, M. E., Grubb, R. L., Gado, M. H., Eichling, J. O., and Ter-Pogossian, M. M. (1976). Correlation between regional cerebral blood flow and oxidative metabolism. In vivo studies in man. Archives of Neurology (Chicago), 33, 523-526.

Risberg, J., Halsey, J. H., Wills, E. L., and Wilson, E. M. (1975). Hemispheric specialization in normal man studied by bilateral measurements of the regional cerebral blood flow. A study with the 133-Xe inhalation technique. Brain, 98, 511-524.

Scheinberg, P., Blackburn, I., Rich, M., and Saslaw, M. (1953). Effects of ageing on cerebral circulation and metabolism. Archives of Neurology and Psychiatry (Chicago), 70, 77-85.

Ter-Pogossian, M. M., Eichling, J. O., Davis, D. O., and Welch, M. J. (1970). The measure in vivo of regional oxygen utilization by means of oxyhemoglobin labelled with radioactive oxygen-15. Journal of Clinical Investigation, 49, 381-391.

Ter-Pogossian, M. M., Phelps, M. E., Hoffman, E. J., and Mullani, N. A. (1975). A positron emission transaxial tomograph for nuclear medicine imaging (PETT). Radiology, 114, 89-98.

West, J. B., and Dollery, C. T. (1962). Uptake of oxygen-15 labelled $\mathrm{CO}_{2}$ compared with carbon-11 labelled $\mathrm{CO}_{2}$ in the lung. Journal of Applied Physiology, 17, 9-13.

Westerman, B. R., and Glass, H. I. (1968). Physical specification of a gamma camera, Journal of Nuclear Medicine, 9, 24-30.

Wilkinson, I. M. S., Bull, J. W. D., Du Boulay, G. H., Marshall, J., Ross Russell, R. W., and Symon, L. (1969). Regional blood flow in the normal cerebral hemisphere. Journal of Neurology, Neurosurgery, and Psychiatry., 32, 367-378. 